The Journal of Engineering and Exact Sciences - jCEC, Vol. 06 N. 05 (2020)

journal homepage: https://periodicos.ufv.br/ojs/jeec

doi: 10.18540/jcecvl6iss5pp0777-0782

OPEN ACCESS - ISSN: 2527-1075

\title{
ANÁLISE DO CÁLCULO DE CARGA TÉRMICA DE UMA CÂMARA DE RESFRIAMENTO DE CARCAÇAS BOVINAS COM CAPACIDADE DE 42 TONELADAS
}

\section{ANALYSIS OF THE CALCULATION OF THE THERMAL LOAD OF A COOLING CHAMBER OF BOVINE CARCASSES WITH A CAPACITY OF 42 TONS}

\section{D. PEREIRA ${ }^{1}$, A. S. OLIVEIRA ${ }^{2}$}

${ }^{1}$ Federal University of Paraná, Department of Mechanical Engineering, Technology Sector, Curitiba, Paraná, Brazil

${ }^{2}$ Federal University of Pernambuco, Department of Nursing, Recife, Pernambuco, Brazil

${ }^{1}$ Federal University of Paraná, Department of Mechanical Engineering, Technology Sector, Curitiba, Paraná, Brazil, Phone: +55 41 3361-3701 e-mail address:durancti@yahoo.com.br (M. D. Pereira).

${ }^{2}$ Federal University of Pernambuco, Department of Nursing, Recife, Pernambuco, Brazil, Phone: $+55812126-3661$

e-mail address:durancti@yahoo.com.br (M. D. Pereira).

\begin{tabular}{l} 
A R T I C L E I N F O \\
\hline Article history: \\
Received 2020-10-13 \\
Accepted 2020-12-20 \\
Available online 2020-12-20 \\
p a l a vra $s-c h a v e$ \\
Câmara de Resfriamento \\
Carga Térmica \\
Refrigeração Industrial \\
$k$ e y wor $d s$ \\
Cooling Chamber \\
Thermal Load \\
Industrial Refrigeration
\end{tabular}

\begin{abstract}
A B S T R A C T
This article had as objectives to calculate the thermal load of a cooling chamber of bovine carcasses with a capacity of 42 tons in $24 \mathrm{~h}$ of process and to verify the factor of greatest influence in this calculation. It was a field research in a cattle slaughterhouse in the city of Rondon do Pará / PA and an exploratory bibliographic research, based on books in the category of industrial refrigeration and scientific articles about it. After calculating the total thermal load, the value of $99170 \mathrm{kcal} / \mathrm{h}$ was reached and the factor with the greatest influence was the product load with approximately 54\% of the total thermal load. This article is relevant because Brazil is one of the largest producers and exporters of animal protein in the world and because the concept of thermal load in a cooling chamber for bovine carcasses is a fundamental step to dimension the industrial refrigeration equipment of a refrigeration cycle.

R E S U M O

O trabalho teve como objetivos calcular a carga térmica de uma câmara de resfriamento de carcaças bovinas com capacidade de 42 toneladas em 24 h de processo e verificar ofator de maior influência neste cálculo. Foi uma pesquisa de campo em um abatedouro de bovinos na cidade de Rondon do Pará/PA e uma pesquisa bibliográfica exploratória, baseada em livros da categoria de refrigeração industrial e trabalhos científicos a respeito. Após se calcular a carga térmica total, chegou-se no valor de $99169 \mathrm{kcal} / \mathrm{h}$ e sendo o fator de maior influência a carga do produto com cerca de 54\% da carga térmica total. Este trabalho possui relevância pois o Brasil é um dos maiores produtores e exportadores de proteina animal do mundo e porque o conceito de carga térmica em uma câmara de resfriamento carcaças bovinas é um passo fundamental para se dimensionar adequadamente os equipamentos de refrigeração industrial de um ciclo frigorifico.
\end{abstract}




\section{INTRODUCÃO}

De acordo com Araújo (2018) e Çengel e Ghajar (2012), controlar a temperatura dos alimentos, levando-os ao resfriamento ou congelamento, é um método de conservação que tem a função de retardar a taxa de crescimento de microrganismos tais como vírus, fungos, leveduras e principalmente as bactérias, evitando-se assim, doenças ao ser humano, além de sabores e odores desagradáveis.

No cenário mundial, o Brasil é hoje um dos países que mais exporta carne no mundo e segundo a Associação Brasileira das Indústrias Exportadoras de Carne (ABIEC, 2019), o país exportou cerca de 1,847 milhões de toneladas, só de carne bovina em 2019. Concordante com Andrade (2014), esse desempenho é consequência do clima favorável à pecuária, à grande extensão de terras com preço mais acessível e vantagens com relação à sanidade do rebanho.

Essa carne para ser exportada, passa por processos de refrigeração, assim como grande parte da carne consumida no mercado interno do país.

Consoante com Ricardo (2010), grandes carcaças geralmente passam por antecâmaras de pré-resfriamento. Entretanto, nesta pesquisa as carcaças bovinas passaram diretamente para a câmara de resfriamento, onde o ar ambiente fica entre $0^{\circ} \mathrm{C} \mathrm{e}+4^{\circ} \mathrm{C}$, segundo Oliveira et al (2019). Ainda em consonância com Sousa (2017), a velocidade de circulação do ar neste ambiente fica entre 0,3 a 1,0 m/s. Para a correta seleção dos equipamentos de refrigeração industrial de uma câmara de resfriamento, tais como compressores, evaporadores, condensadores evaporativos, separadores de líquido, depósitos de líquido, sistemas de expansão, é importante calcular a carga térmica da mesma. A carga térmica de uma câmara de resfriamento de carcaças bovinas pode ser definida como a quantidade de calor que se deve retirar do ambiente e do produto (carne bovina), por unidade de tempo.

Como objetivos deste trabalho, têm-se o de calcular a carga térmica de uma câmara de resfriamento de bovinos com capacidade de 42 toneladas existente em um abatedouro de bovinos na cidade de Rondon do Pará/PA e analisar os fatores de maior influência neste cálculo.

Esse cálculo de carga térmica se justifica porque é através dele que se dimensiona adequadamente os equipamentos de refrigeração industrial e este trabalho tenta contribuir nos projetos do segmento de refrigeração industrial, haja visto que a grande maioria dos trabalhos feitos anteriormente sobre cálculo de carga térmica são voltados para ambientes residenciais, ou seja, de conforto térmico.

\section{MATERIAIS E MÉTODOS}

Refere-se à uma pesquisa de campo em um abatedouro de bovinos localizado na cidade de Rondon do Pará/PA, realizada no segundo semestre de 2019. Neste frigorífico de bovinos que, baseado em Kruger (2016), é um estabelecimento industrial que possui capacidade de abater e processar as carcaças, tendo-se a segurança que o produto final encaixe-se nos padrões exigidos pelos clientes, foram realizadas visitas para colher os dados da câmara de resfriamento em estudo, como dimensões, capacidade de resfriamento, tempo de processo, o fluido refrigerante utilizado no ciclo de refrigeração, qual o tipo de isolamento e sua respectiva espessura, temperaturas de entrada e saída das carcaças, temperaturas do ar externo, quantidade dos evaporadores existentes dentro do ambiente, potência de iluminação, fotografias. Foi realizada uma medição de dimensões realizada através de fita métrica e os dados de temperatura foram coletados com os engenheiros e técnicos do abatedouro de aves e conferidos presencialmente através de um termosensor. A margem de erro estimada está em torno de $10 \%$, pois alguns autores como Stoecker e Jabardo (2018) sugerem acrescentar $10 \%$ de fator de segurança para compensar eventuais distorções. Foi utilizado o software Autocad para fazer uma representação geométrica da câmara de resfriamento e também para retratar o fluxograma de interligação dos equipamentos do ciclo frigorífico. Adicionalmente, o artigo se refere à uma pesquisa bibliográfica exploratória, em que se baseou em informações de alguns livros e trabalhos científicos do segmento de refrigeração industrial que possuem estudos sobre cálculo de carga térmica para resfriamento de carcaças bovinas.

\section{RESULTADOS E DISCUSSÕES}

No decorrer das visitas ao abatedouro de bovinos que se localiza na cidade de Rondon do Pará/PA, foram coletadas as dimensões de comprimento, largura, altura da câmara de resfriamento em estudo, além da espessura de isolamento. Como são três câmaras de resfriamento de mesma capacidade, se fez um estudo de somente uma câmara de resfriamento. A partir dessas informações, foi realizado uma representação geométrica simplificada, conforme Figura 1:

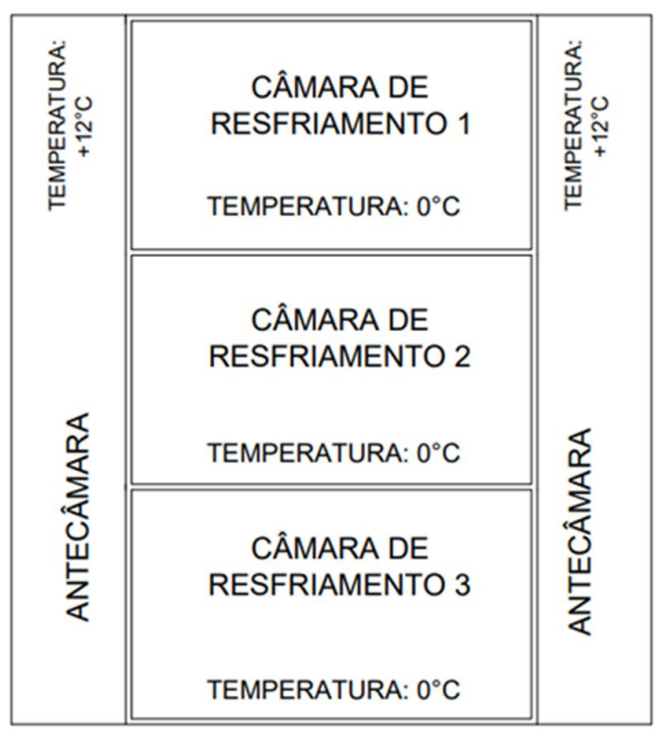

Figura 1 - Representação da câmara de resfriamento de carcaças bovinas. Fonte: Os autores (2020). 
No interior dessa câmara de resfriamento em estudo, há os evaporadores de ar forçado que são os equipamentos frigoríficos responsáveis por retirar o calor do ar e das carcaças bovinas. Eles possuem motoventiladores e ficam posicionados na parte superior e lateral da câmara, conforme demonstrado na Figura 2:

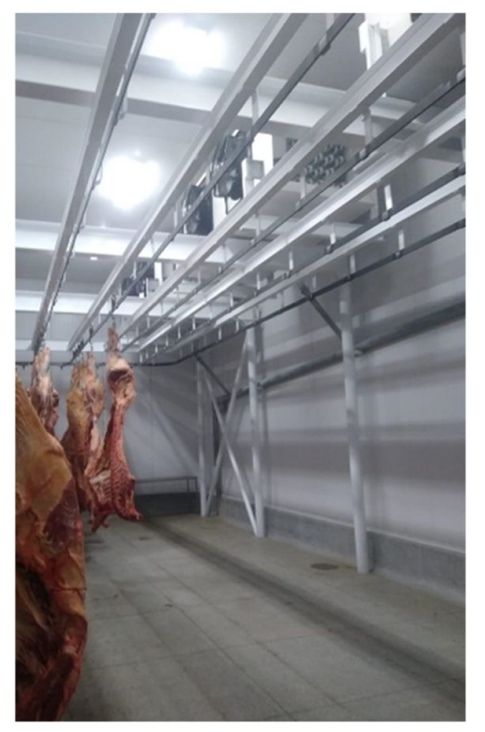

Figura 2 - Evaporadores de ar forçado da câmara de resfriamento. Fonte: Os autores (2020).

Entretanto, os demais equipamentos do ciclo de refrigeração industrial encontram-se remotamente interligados por tubulações, tais como os compressores, condensador evaporativo, reservatório de líquido, separador de líquido, bombas de amônia e dispositivo de expansão. Para representar estes equipamentos mencionados, fez-se um fluxograma de interligação, conforme Figura 3:

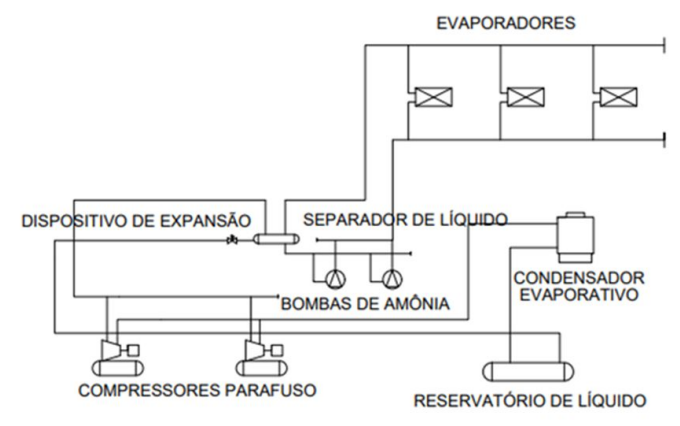

Figura 3 - Representação do fluxograma de interligação dos equipamentos do ciclo de refrigeração industrial. Fonte: Os autores (2020).

As carcaças bovinas entram na câmara de resfriamento em uma temperatura próxima de $+40^{\circ} \mathrm{C}$ e a temperatura de saída fica entre $-1^{\circ} \mathrm{C}$ à $+2 \mathrm{C}$ e as mesmas ficam penduradas, conforme Figura 4:

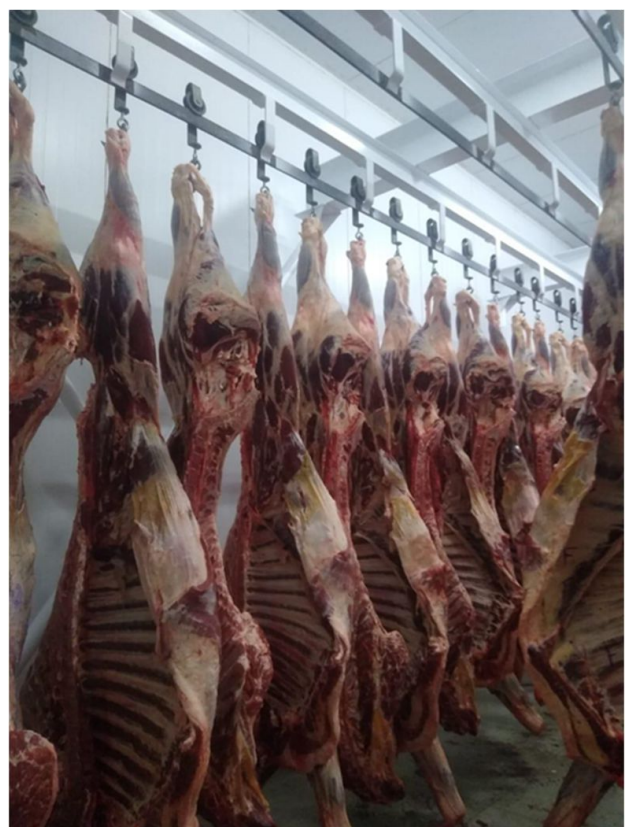

Figura 4 - Carcaças bovinas penduradas na câmara de resfriamento. Fonte: Os autores (2020).

A partir das visitas ao abatedouro de bovinos, se criou a Tabela 1, com os dados para se poder calcular a carga térmica da câmara de resfriamento:

Table 1 - Dados para cálculo da câmara de resfriamento de carcaças bovinas

\begin{tabular}{|l|c|}
\hline $\begin{array}{l}\text { Capacidade de resfriamento da } \\
\text { câmara }\end{array}$ & $42.000 \mathrm{~kg}$ \\
\hline Fluido refrigerante & Amônia $\left(\mathrm{NH}_{3}\right)$ \\
\hline Tempo de resfriamento & $24 \mathrm{~h}$ \\
\hline $\begin{array}{l}\text { Dimensões (comprimento } \mathrm{x} \\
\text { largura x altura) }\end{array}$ & $14,00 \times 8,00 \times 6,00 \mathrm{~m}$ \\
\hline $\begin{array}{l}\text { Temperatura de entrada da } \\
\text { carcaça bovina }\end{array}$ & $+40^{\circ} \mathrm{C}$ \\
\hline $\begin{array}{l}\text { Temperatura de saída da } \\
\text { carcaça bovina }\end{array}$ & \\
\hline $\begin{array}{l}\text { Temperatura do ar externo } \\
\text { (antecâmara) }\end{array}$ & $+12^{\circ} \mathrm{C}$ \\
\hline Temperatura ar externo ("rua”) & $+35^{\circ} \mathrm{C}$ \\
\hline Tipo de isolamento & Poliestireno expandido \\
\hline Espessura de isolamento & $200 \mathrm{~mm}$ \\
\hline
\end{tabular}

Conforme Costa (1982), subdivide-se em quatro fatores principais o cálculo de carga térmica total de um frigorífico de refrigeração industrial: carga térmica pelo produto $(\mathrm{Qh})$, carga térmica pela infiltração do ar externo $(\mathrm{Q} a)$, carga térmica de penetração $(\mathrm{Qp})$ e carga térmica por fatores diversos $(\mathrm{Qd})$. 


\subsection{Carga térmica pela pelo produto $(\mathrm{Qh})$}

A carga térmica pelo produto $(\mathrm{Qh})$ para a câmara de resfriamento em estudo, se refere ao calor sensível que se deve retirar das carcaças bovinas da temperatura de entrada até a temperatura de saída. Concordante com Melo (1977), as diferenças entre os bovinos são complexas. Há fatores que influenciam no cálculo das propriedades térmicas da carne, tais como: espécie, raça, sexo, tamaho, peso, idade e tipo de exercícios feitos pelo animal antes do abate. Adicionalmente, com base em Prado, Bueno e Felício (2007), a perda de peso da carcaça bovina durante o resfriamento pode ser de $0,75 \%$ a $2 \%$. Para tanto, fizeram-se considerações para facilitar o cálculo de carga térmica pelo produto na sequência. Segundo LONCAN (2019), o cálculo da carga térmica pelo produto (Qh) pode ser realizado pela Equação 1:

$Q h=\frac{m X c X(t i-t f)}{\tau}$

Onde:

$\mathrm{Qh}=$ Carga térmica pelo produto $[\mathrm{kcal} / \mathrm{h}]$

$\mathrm{m}=$ Massa da carcaça bovina a se resfriar $[\mathrm{kg}]$

$\mathrm{c}=$ Calor específico da carcaça bovina antes do congelamento $\left[\mathrm{kcal} / \mathrm{kg}^{\circ} \mathrm{C}\right]$

$\mathrm{ti}=$ Temperatura inicial (de entrada) da carcaça bovina $\left[{ }^{\circ} \mathrm{C}\right]$

$\mathrm{tf}=$ Temperatura final (de saída) da carcaça bovina $\left[{ }^{\circ} \mathrm{C}\right]$

$\tau=$ Tempo de processo (resfriamento) $[\mathrm{h}]$

Para a câmara de resfriamento existente e que está em estudo neste trabalho, a massa de carcaças bovinas é de 42000 $\mathrm{kg}$, utilizando-se o calor específico da carcaça bovina antes do congelamento de $0,7690838 \mathrm{kcal} / \mathrm{kg}^{\circ} \mathrm{C}$, temperatura de entrada das carcaças bovinas de $+40^{\circ} \mathrm{C}$, temperatura de saída de $0^{\circ} \mathrm{C}$ e empregando-se a Equação 1, chega-se a uma carga térmica pelo produto $(\mathrm{Qh})$ no valor de $53835 \mathrm{kcal} / \mathrm{h}$.

\subsection{Carga térmica pela infiltração do ar externo (Qa)}

Segundo Melo (2018), a carga térmica pela infiltração do ar externo é função direta do calor que infiltra pelas aberturas (frestas) da câmara de resfriamento, especialmente pelas portas, em que há uma renovação do ar. Sendo que a infiltração adiciona calor sensível e calor latente ao ambiente. Para este fator, deve-se primeiramente calcular o índice de renovação do ar externo (n), que é um valor considerado pequeno para grandes dimensões de câmaras e, em contrapartida, grande para câmaras de pequenas dimensões. Conforme LONCAN (2019), o índice de renovação (n) pode ser calculado pela Equação 2:

$n=\frac{3 X p \times S p \times \tau p}{(V)^{0,5}}$

Sendo:

$\mathrm{n}=$ Índice de renovação [renovações $/ \mathrm{h}$ ] $\mathrm{p}=$ Número de portas []

$\mathrm{Sp}=$ Seção do vão livre de cada porta $\left[\mathrm{m}^{2}\right]$

$\tau \mathrm{p}=$ Tempo de abertura de cada porta $[\mathrm{h}]$

$\mathrm{V}=$ Volume do túnel de congelamento $\left[\mathrm{m}^{3}\right]$

$\mathrm{Na}$ câmara de resfriamento existente em estudo, há duas portas (p), a seção livre de cada porta (Sp) é de 5,44 $\mathrm{m}^{2}$, o tempo de abertura é ( $\tau p)$ é de $1 \mathrm{~h}$, o volume da câmara de resfriamento é de $672 \mathrm{~m}^{3}$. Utilizando a Equação 2, chega-se ao índice de renovação (n) de 1,25912 renovações/h.

Após calcular o índice de renovação (n), pode-se agora calcular propriamente a carga térmica pela infiltração do ar externo (Qa) pela Equação 3:

$Q a=n x V x(H e-H i) x \gamma e$

Em que:

$\mathrm{Qa}=$ Carga térmica pela infiltração de ar externo [kcal/h]

$n=$ Índice de renovação do ar externo [renovações/h]

$\mathrm{V}=$ Volume do túnel de congelamento $\left[\mathrm{m}^{3}\right]$

$\mathrm{He}=$ Entalpia do ar externo $[\mathrm{kcal} / \mathrm{kg}]$

$\mathrm{Hi}=$ Entalpia do ar interno $[\mathrm{kcal} / \mathrm{kg}]$

$\gamma e=$ Peso específico do ar externo $\left[\mathrm{kg} / \mathrm{m}^{3}\right]$

Utilizando o software MpsyCalc da Munters (2019), chegou-se a dados psicrométricos da entalpia do ar externo (He) de $21,62285 \mathrm{kcal} / \mathrm{kg}$, da entalpia do ar interno de 2,03394 $\mathrm{kcal} / \mathrm{kg}$, o peso específico do ar externo de $1,14600 \mathrm{~kg} / \mathrm{m}^{3}$. Utilizando a Equação 3, chega-se à carga térmica pela infiltração de ar externo (Qa) de $18994 \mathrm{kcal} / \mathrm{h}$.

\subsection{Carga térmica de penetração (Qp)}

A carga térmica de penatração (Qp) se refere ao calor que penetra pelo isolamento térmico adotado do teto, piso e das paredes da câmara de resfriamento. Conforme Loncan (2019), através da Equação 4 pode-se encontrar a carga térmica de penetração:

$Q p=($ Steto + Spiso + Sparedes $) x\left(\frac{K i}{e i}\right) x(t e-t i)$

Onde:

$\mathrm{Q}_{\mathrm{p}}=$ Carga térmica por penetração $[\mathrm{kcal} / \mathrm{h}]$

$\mathrm{S}_{\text {teto }}=$ Superficie total do teto $\left[\mathrm{m}^{2}\right]$

$\mathrm{S}_{\mathrm{piso}}=$ Superfície total do piso $\left[\mathrm{m}^{2}\right]$

$\mathrm{S}_{\text {paredes }}=$ Superficie total das paredes $\left[\mathrm{m}^{2}\right]$

$\mathrm{Ki}=$ Condutividade térmica do material isolante $\left[\mathrm{kcal} / \mathrm{hm}^{\circ} \mathrm{C}\right]$ 
$\mathrm{e}_{\mathrm{i}}=$ Espessura de isolamento [m]

te $=$ Temperatura externa $\left[{ }^{\circ} \mathrm{C}\right]$

$\mathrm{ti}=$ temperatura interna $\left[{ }^{\circ} \mathrm{C}\right]$

Foram utilizadas as dimensões da câmara de resfriamento real em estudo e que são mostradas no Quadro 1. $\mathrm{O}$ coeficiente de condutividade térmica do material (poliestireno expandido - EPS) de 0,03009 $\mathrm{kcal} / \mathrm{hm}^{\circ} \mathrm{C}$, espessura de isolamento de $200 \mathrm{~mm}$, temperatura externa para o teto de $+40^{\circ} \mathrm{C}$, temperatura externa para o piso de $+30^{\circ} \mathrm{C}$, temperatura externa para a parede sul de $0^{\circ} \mathrm{C}$ (outra câmara de resfriamento), temperatura externa para a parede norte de $+35^{\circ} \mathrm{C}$ ("rua"), temperatura das paredes leste e oeste (antecâmaras) de $+12^{\circ} \mathrm{C}$, temperatura interna da câmara de resfriamento de $0^{\circ} \mathrm{C}$, chegouse à uma carga térmica de penetração $(\mathrm{Qp})$ de $1795 \mathrm{kcal} / \mathrm{h}$.

\subsection{Carga térmica por fatores diversos $(\mathrm{Qd})$}

A carga térmica por fatores diversos $(\mathrm{Qd})$ da câmara de resfriamento em estudo corresponde à soma do calor que é gerado por motores elétricos dos evaporadores de convecção forçada $(\mathrm{Qm})$ e à iluminação $(\mathrm{Q} i)$. Adicionalmente, se considera a carga térmica gerada pelo metabolismo das pessoas (Qpe) para áreas de climatização ou câmaras de estocagem, entretanto para esta câmara de resfriamento não será considerado este fator Qpe, pois não há circulação de pessoas no interior da câmara durante o processo de resfriamento.

\subsubsection{Carga térmica devido à iluminação (Qi)}

Conforme Loncan (2019), pode-se calcular a parcela de carga térmica gerada pela iluminação (Qi) pela Equação 5:

$Q i=W x 0,86$

Sendo:

$\mathrm{W}=$ Potência de iluminação instalada [W]

Qi = Carga térmica pela iluminação $[\mathrm{kcal} / \mathrm{h}]$

Sendo considerado 6 lâmpadas de 100 w cada e utilizando a Equação 5, chegou-se à uma carga térmica devido à iluminação de $516 \mathrm{kcal} / \mathrm{h}$.

\subsubsection{Carga térmica devido aos motores dos evaporadores (Qm)}

Conforme Loncan (2019), a carga térmica devido aos motores dos evaporadores $(\mathrm{Qm})$ pode ser calculada através da Equação 6:

$Q m=\left(\frac{C V}{F S}\right) \times 632$
$\mathrm{Q}_{\mathrm{m}}=$ Carga térmica pelos motores dos evaporadores $[\mathrm{kcal} / \mathrm{h}]$

$\mathrm{CV}=$ Potência instalada dos motores [CV]

FS = Fator de segurança adotado na seleção dos motores [1,2]

$632=$ Fator de conversão kcal/h.CV.

Considerando-se 6 motores de 7,5 HP cada um $(45,62413 \mathrm{CV}$ no total) e utilizando a Equação 6, chega-se à uma carga térmica devido aos motores de $24029 \mathrm{kcal} / \mathrm{h}$.

Conforme mencionado anteriormente, a carga térmica por fatores diversos (Qd) é a soma do fator de iluminação (Qi) e o fator de carga térmica pelos motores dos evaporadores $(\mathrm{Qm})$. Somando-se estes dois fatores, chegou-se à carga térmica por fatores diversos (Qd) de $24545 \mathrm{kcal} / \mathrm{h}$.

\subsection{Carga térmica total}

Somando-se todas as cargas térmicas parciais (Qa, Qp, Qh e Qd), chega-se na carga térmica total (Qt), conforme Equação 7:

$Q t=Q a+Q p+Q h+Q d$

Onde:

$\mathrm{Q} \mathrm{t}=$ Carga térmica total $[\mathrm{kcal} / \mathrm{h}]$

$\mathrm{Qa}=$ Carga térmica pela infiltração do ar externo [ $\mathrm{kcal} / \mathrm{h}]$

$\mathrm{Qp}=$ Carga térmica de penetração $[\mathrm{kcal} / \mathrm{h}]$

$\mathrm{Qh}=$ Carga térmica pelo produto $[\mathrm{kcal} / \mathrm{h}]$

$\mathrm{Qd}=$ Carga térmica por fatores diversos $[\mathrm{kcal} / \mathrm{h}]$

Utilizando-se a Equação 7, chegou-se à uma carga térmica total (Qt) de $99169 \mathrm{kcal} / \mathrm{h}$.

Após o cálculo de carga térmica, fez-se um gráfico com a distribuição dos fatores de carga térmica, conforme Figura 5:

DISTRIBUIÇAO DOS FATORES DE CARGA TERMICA

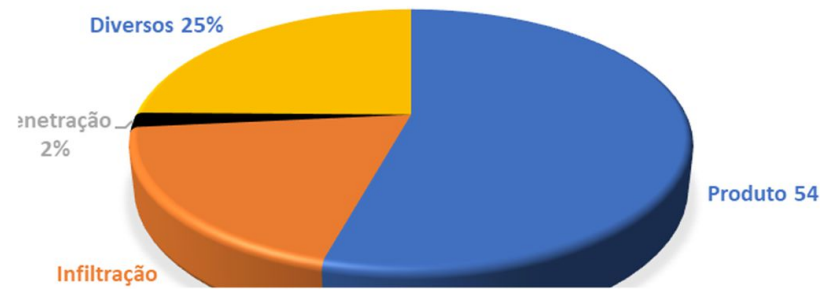

Figura 5 - Distribuição dos fatores de carga térmica. Fonte: os autores (2020).

Onde: 


\section{CONCLUSÃO}

Após se calcular a carga térmica para a câmara de resfriamento de carcaças bovinas com capacidade de 42 toneladas é $99169 \mathrm{kcal} / \mathrm{h}$. Normalmente os projetistas colocam um fator de segurança de cerca de $10 \%$ para posterior seleção dos equipamentos do ciclo frigorífico. Neste trabalho, não se colocou estes $10 \%$ porque não há a preocupação com uma seleção dos equipamentos. Também se verificou que o fator de maior de maior influência no cálculo de carga térmica é devido ao produto, no caso as carcaças bovinas, com cerca de $54 \%$ da carga térmica total.

\section{REFERÊNCIAS}

ANDRADE, Patrícia Bueno. Avaliação físico-química de meias-carcaças bovinas resfriadas e de cortes desossados sob emprego do filme stretch. Universidade Federal de Goiás, 2014.

ARAÚJO, Marcela Carneiro. Análise comparativa entre a capacidade frigorífica e carga térmica de armazéns climatizados. Universidade de Uberlândia (UFU). Uberlândia, 2018.

ASSOCIAÇÃO BRASILEIRA DAS INDÚSTRIAS EXPORTADORAS DE CARNES (ABIEC). Exportações. Disponível em: $<$ http://abiec.com.br/exportacoes/> Acesso em: 12 set. 2020.

ÇENGEL, Yunus A.; GHAJAR, Afshin J. Transferência de calor e massa: uma abordagem prática. Porto Alegre: AMGH, 2012.

COSTA, Ennio Cruz da. Refrigeração. São Paulo: Blucher, 1982.

KRUGER, Priscila. Perda de peso por desidratação no resfriamento de carcaças suínas. Universidade Tecnológica Federal do Paraná, 2016.

LONCAN, Paulo. Projeto de instalações frigoríficas. Porto Alegre: Editora da UFRGS, 2019.

MELO, G. S. Resfriamento de meias-carcaças de bovinos. Dissertação de mestrado em Engenharia de Alimentos FEA, 185 p, 1977.

MELO, Marcus Vinicius Silvestrin de. Projeto de uma fábrica de pescado utilizando túnel de congelamento e câmara de estocagem com o fluido refrigerante R404A. Universidade Federal de Uberlândia. Uberlândia, MG, 2018.

MUNTERS Psycalc. Versão 5.1, 2019.

OLIVEIRA, Janderson Ananias de; NETO; Angelo Polizel; FORTUNA, Natália Baldasso; GROTH, Andressa; VITEK, Rafaela Raiany; ROSA, Claudineli Cássia Bueno. Sistema de aspersão de água sobre carcaças bovinas durante o resfriamento e seus efeitos sobre a qualidade microbiológica da carne. Universidade Federal de Mato Grosso, 2019.

PRADO, Cristiano Sales; BUENO, Claúdia Peixoto; FELÍCIO, Pedro Eduardo de. Aspersão de água fria no início do resfriamento de carcaças bovinas e maturação da carne sobre o peso, cor e aceitação do músculo longissimus lumborum. Ciência Animal Brasileira, 2007.

RICARDO, Hélio de Almeida. Resfriamento de carcaças de ruminantes. Pubvet, Londrina, 2010.

SOUSA, Carla Magalini Zago. Uso do frio na conservação de carcaças bovinas: uma revisão. Brasília, Distrito Federal, 27 p, 2017.

STOECKER, Wilbert F.; JABARDO, José M. Saiz. Refrigeração industrial. $3^{\mathrm{a}}$ edição. São Paulo: Blucher, 2018. 